\title{
Note
}

\section{Effect of a Desiccant on the Measurement of Radon Concentration in Air}

\author{
Yukari TAлIKA, ${ }^{* 1}$ Yumi YasuOKA, ${ }^{* 1}$ Yasutaka OMORI, ${ }^{* 2}$ Atsuyuki SorimachI, ${ }^{* 3}$ Tetsuo IshIKAWA, ${ }^{* 4}$ \\ Yasunori MORI*5 and Takahiro MukAI*1
}

(Received on December 3, 2013)

(Accepted on October 16, 2014)

\begin{abstract}
Anhydrous calcium sulfate has been identified for use as a desiccant in radon monitoring. However, the influence of a desiccant on radon measurements has not been investigated. Therefore, AlphaGUARD monitors working in flow mode with and without a desiccant, and in diffusion mode as reference were used for radon measurements in the radon chamber at the National Institute of Radiological Sciences, Japan. The radon concentration in the air in the radon chamber was maintained at a constant level and measured at three levels of relative humidity: low, normal and high. Comparison of the results with the reference value showed that the differences were below $4 \%$, which is within the acceptable range (below $10 \%$ ). Consequently, when radon concentration was measured with the desiccant, we considered that the influence of the desiccant can be ignored.
\end{abstract}

KEY WORDS: radon, desiccant, radon chamber, AlphaGUARD, Anhydrous calcium sulfate.

\section{INTRODUCTION}

The World Health Organization has proposed a reference level of $100 \mathrm{~Bq} \mathrm{~m}^{-3}$ to minimize health hazards due to indoor radon exposure. ${ }^{1,2)}$ When different methods for measuring radon concentrations in the air are employed under certain conditions, the concentration data may be influenced by moisture., ${ }^{3)}$ In such cases, desiccants have been used to eliminate the influence of moisture. Such desiccants include phosphorous pentoxide (toxic compound), ${ }^{5,6)}$ calcium chloride (deliquescent material) and silica gel (absorbs a small amount of radon). ${ }^{7)}$ Radon concentration in high humidity can be measured with the commercially available AlphaGUARD (PQ-2000, Genitron Instruments GmbH, Germany) without using a desiccant. ${ }^{8,9)}$ Moreover, radon released from bubbled water has been measured with the AlphaGUARD without the use of a desiccant. ${ }^{10,11)}$ However, it is desirable to prevent high humidity air from entering the AlphaGUARD ionization chamber; the AlphaGUARD is a well-known and wellregarded continuous radon monitor.

All authors' Institutions at the time of submitting this paper.

*1 Kobe Pharmaceutical University; 4-19-1 Motoyamakita-machi, Higashinada-ku, Kobe-shi, Hyogo 658-8558, Japan.

E-mail: yasuoka@kobepharma-u.ac.jp

*2 National Institute of Radiological Sciences; 4-9-1 Anagawa, Inageku, Chiba-shi, Chiba 263-8555, Japan.

*3 Hirosaki University; 66-1 Hon-cho, Hirosaki-shi, Aomori 0368564, Japan.

*4 Fukushima Medical University; 1 Hikarigaoka, Fukushima-shi, Fukushima 960-1295, Japan.

*5 Mie Prefecture Health and Environment Research Institute; 3684-11 Sakura-cho, Yokkaichi-shi, Mie 512-1211, Japan.
When air at $80 \%$ relative humidity $(\mathrm{RH})$, and that passed through a desiccant was injected into an ionization chamber containing ${ }^{241} \mathrm{Am}$, the humidity had a very limited effect on the recorded results. ${ }^{12)}$ Recently, anhydrous calcium sulfate has been employed as a desiccant when measuring radon concentrations with the RAD7 (Durridge Company Inc., USA) radon monitor ${ }^{13,14)}$ and the Trace Environmental Level detector (Pylon Electronics Inc., Canada). ${ }^{15)}$ However, the influence of anhydrous calcium sulfate on radon measurements during testing in a radon chamber equipped with systems to control radon concentration and humidity has not been clarified.

The purpose of the present study was to observe whether using the desiccant has any effect on radon concentration measurements. Therefore, a single AlphaGUARD working in flow mode ( $\mathrm{F}$ mode-AG) and a second AlphaGUARD working in diffusion mode (D mode-AG) were applied to measure radon in the radon chamber at the National Institute of Radiological Sciences (NIRS), Japan. The NIRS radon chamber $\left(24.4 \mathrm{~m}^{3}\right)$ has systems to control radon concentration, temperature and humidity. ${ }^{16,17)}$

\section{METHOD}

The air in the radon chamber (chamber air) was maintained at a radon concentration level of 7,000 to $8,000 \mathrm{~Bq} \mathrm{~m}^{-3}$ at around $22^{\circ} \mathrm{C}$ with three levels of $\mathrm{RH}, 31 \%$ (low level), $56 \%$ (normal level) and 74\% (high level). The normal environmental RH condition in the chamber when operating in D mode-AG was approximately $60 \%$. The air was filtered to eliminate radon progeny, and then the radon concentration was measured with the AlphaGUARD devices every 10 min for $510 \mathrm{~min}$ (The sample size in each experiment was 51). 
A rigid cylinder $(6.7 \mathrm{~cm}$ in diameter and $29.9 \mathrm{~cm}$ long) containing $500 \mathrm{~g}$ of anhydrous calcium sulfate (Drierite 8 mesh, Stock No. 26800, W. A. Hammond Drierite Company, Ltd., USA) was used to absorb moisture. (Detailed specifications can be found in the 'Drierite desiccant catalog'18) $)$. The air with RH greater than $90 \%$ was dried to $10 \% \mathrm{RH}$ or less through the desiccant at around $22^{\circ} \mathrm{C}$ by the flow rate of $5 \times 10^{-4} \mathrm{~m}^{3} \mathrm{~min}^{-1}$. This dehydration was maintained for approximately 3 days without replacing the desiccant (data not shown).

A single AlphaGUARD operating in F mode-AG (flow rate: $\left.5 \times 10^{-4} \mathrm{~m}^{3} \mathrm{~min}^{-1}\right)^{19)}$ and a second AlphaGUARD operating in $\mathrm{D}$ mode-AG were used to measure radon in the chamber air. In the first test $(\mathrm{N}-\mathrm{I})$, the radon in the air, which had been dried by the desiccant, was measured with the monitor operating in $\mathrm{F}$ mode- $\mathrm{AG}$, and the radon concentration in air with differing $\mathrm{RH}$ levels was measured with the monitor operating in $\mathrm{D}$ mode-AG. In the second test $(\mathrm{N}-\mathrm{II})$, the radon with differing levels of RH was measured with the monitor in both F modeAG and D mode-AG (Fig. 1).

\section{RESULTS AND DISCUSSION}

Figure 2 shows the relationship between radon concentration and RH. For the three levels of RH $(31 \%, 56 \%$ and $74 \%$ ), a comparison of D mode-AG N-I results (grey dots) with D mode-AG N-II results (black dots) showed that the levels of radon concentration did not differ significantly ( $p$ value $>0.05$ by unpaired $t$-test). The reference value was defined as the mean radon concentration, which was measured

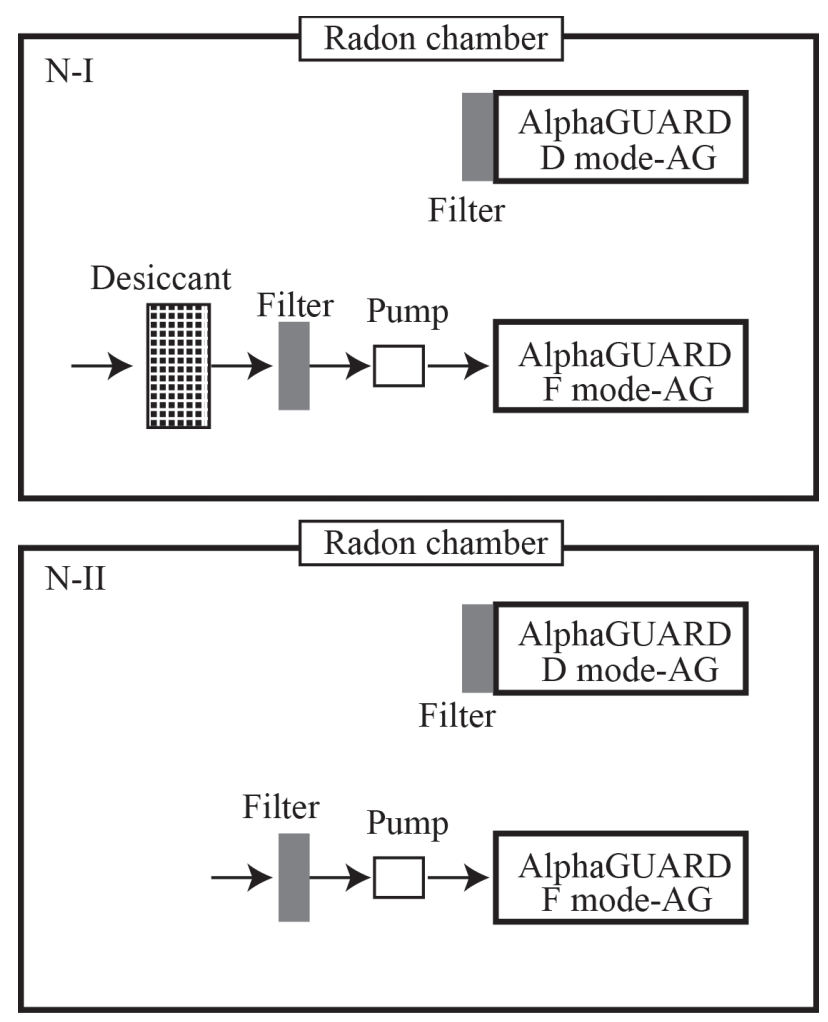

Fig. 1 Schematic diagrams of experiment setup with and without a desiccant (N-I and N-II, respectively).

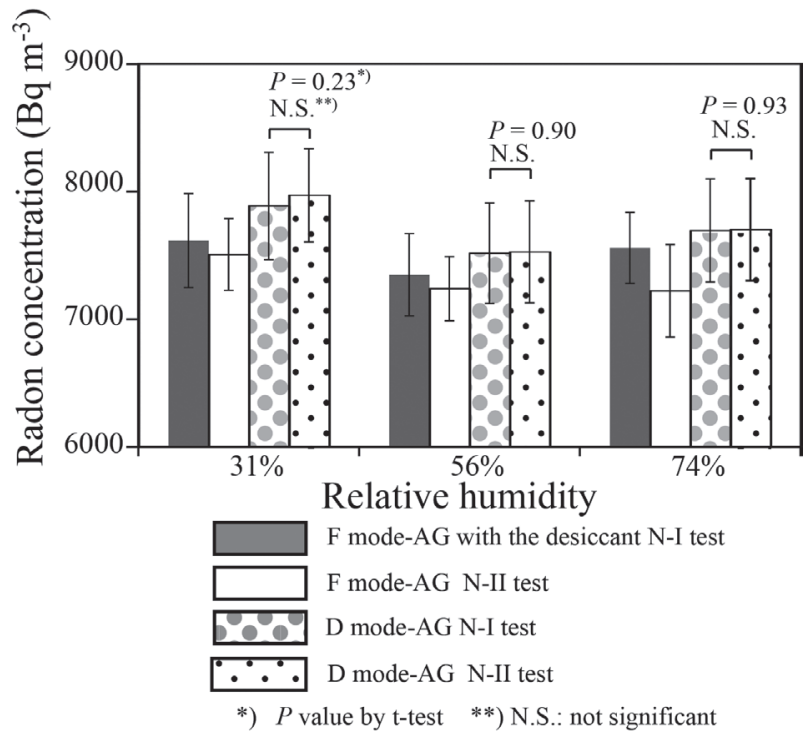

Fig. 2 Relationship between radon concentration and relative humidity. Error bars represent one standard deviation.

in $\mathrm{D}$ mode- $\mathrm{AG}$ for each experiment. When the mean value observed in $\mathrm{F}$ mode-AG was compared with the reference value in each experiment, the acceptable difference was defined as $10 \%$. This difference was established because typical uncertainty of a continuous radon monitor has been reported to be less than $10 \%{ }^{2}{ }^{2}$

The relative radon concentration was defined as the ratio of each value of the F mode-AG to each reference value in each experiment. The relative values are shown in Fig. 3. Each measured value for operation in $\mathrm{F}$ mode-AG in N-I (solid grey) was significantly lower ( $p$ value $<0.01$ by paired $t$-test) than each reference value (grey dots). The difference between the measured and reference values was less than $4 \%$, which is less than the acceptable difference. As a result, when radon concentration was measured with the desiccant ( $\mathrm{F}$ mode-AG, $\mathrm{N}-\mathrm{I}$ ), we considered that the influence of the desiccant can be ignored.

As shown in Fig. 3, in N-II, all values from measurements in F mode-AG (white) were significantly lower ( $p$ value $<0.0001$ by paired $t$-test) than the reference value (black dots). Here the difference between the measured and reference values was less than $6 \%$, which is less than the acceptable difference. Therefore, values obtained in F mode-AG in N-I (solid grey) were significantly higher ( $p$ value $<0.05$ by unpaired $t$-test) than those in N-II (white) for the reasons described below.

The AlphaGUARD detects radon by measuring the electric current generated when the gaseous matters in the chamber are ionized by alpha particles. Radon decays to radon progeny in the AlphaGUARD ionization chamber, and then the radon progeny are oxidized. When the humidity is low, the radon progeny tend to form unattached fractions..$^{20,21)}$ Under such conditions, the radon progeny are considered to remain in the ionization chamber because the oxidized progeny are attracted to the negative electrode, and the radiation emitted from the 


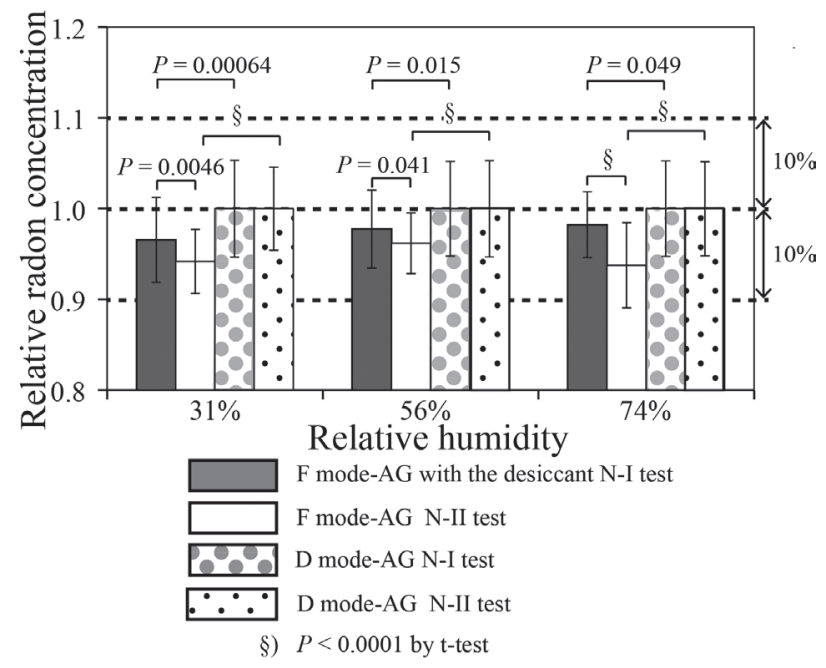

Fig. 3 Relationship between relative radon concentration and relative humidity. Error bars represent one standard deviation.

progeny is considered to be also counted. However, when the humidity is high, there is a possibility that number of the radon progeny attached on water vapour increases, ${ }^{22,23)}$ and these progeny tend to be evacuated from the ionization chamber without being attracted to the negative electrode. Therefore, the alpha particles are reduced in the ionization chamber, when the humidity is high.

\section{CONCLUSIONS}

The influence of anhydrous calcium sulfate employed as the desiccant on the radon measurements was tested in the NIRS radon chamber that has systems to control radon concentration and humidity. The air in the radon chamber was maintained at a constant radon concentration level and exposed to three levels of relative humidity $(31 \%, 56 \%$ and $74 \%)$.

Two tests, N-I and N-II, were performed; the results are presented in Figs. 2 and 3. All results for measurements taken when the monitor was operating in $\mathrm{F}$ mode-AG were significantly lower than the reference values (D mode-AG). However, the differences were less than $6 \%$, which is within the acceptable range, i.e. less than $10 \%$. In $\mathrm{F}$ mode-AG, the N-I results with the desiccant were closer to the reference values than those without the desiccant. We consider that the use of the desiccant countered the influence of moisture, thus the use suppressed a decrease in radiation detection efficiency.

\section{REFERENCES}

1) WORLD HEALTH ORGANIZATION (WHO); "WHO Guidelines for Indoor Air Quality: Selected Pollutants" (2010), WHO Regional Office for Europe, Copenhagen, Denmark.

2) WORLD HEALTH ORGANIZATION (WHO); "WHO Handbook on Indoor Radon: A Public Health Perspective" (2009), World Health Organization, Geneva, Switzerland.

3) A. C. George; State-of-the-art instruments for measuring radon/thoron and their progeny in dwellings: a review, Health Phys., 70, 451-463 (1996).

4) UNITED NATIONS SCIENTIFIC COMMITTEE ON THE EFFECTS OF ATOMIC RADIATION (UNSCEAR); Sources and Effects of Ionizing Radiation. United Nations Scientific Committee on the Effects of Atomic Radiation, 2000 Report to the General Assembly, with Scientific Annexes, Volume I, United Nations Publication, New York (2000).

5) T. IIDA; Passive integrating radon monitor, Jpn. J. Health Phys., 20, 407-415 (1985) (in Japanese).

6) K. Yoshioka; Atmospheric diffusion process based on time change of ${ }^{222} \mathrm{Rn}$ vertical profile, J. Aerosol Res., 17, 267-275 (2002) (in Japanese).

7) R. Kurosawa; Monitoring of radon concentration in dwellings, Radioisotopes, 40, 373-382 (1991) (in Japanese).

8) E. Vogiannis, D. Nikolopoulos, A. Louizi and C. P. HaLVADAKIS; Radon exposure in the thermal spas of Lesvos Island-Greece, Radiat. Prot. Dosim., 111, 121-127 (2004).

9) T. Ishikawa, Y. Yasuoka, S. Tokonami, H. Takahashi and H. SudA; Characterization of airborne radon released by domestic showering and the use of a washing machine, $J$. Radioanal. Nucl. Chem., 279, 719-724 (2009).

10) E. Vogiannis, D. Nikolopoulos, A. Louizi and C. P. HALVADAKIS; Radon variations during treatment in thermal spas of Lesvos Island (Greece), J. Environ. Radioact., 75, 159-170 (2004).

11) V. Radolić, B. Vuković, G. Šmit, D. Stanić and J. Planinić; Radon in the spas of Croatia, J. Environ. Radioact., 83, 191-198 (2005).

12) Y. IsHimori; Characteristics of ${ }^{222} \mathrm{Rn}$ measurement with a gas-filled ionization chamber, Radioisotopes, 54, 599-608 (2005) (in Japanese).

13) C. Y. H. ChaO, T. C. W. Tung, D. W. T. Chan and J. BuRneTt; Determination of radon emanation and back diffusion characteristics of building materials in small chamber tests, Build. Environ., 32, 355-362 (1997).

14) N. M. Hassan, M. Hosoda, K. Iwaoka, A. Sorimachi, M. Janik, C. Kranrod, S. S. Kumar, T. Ishikawa, H. Yonehara, M. Fukushi and S. ToKonami; Simultaneous measurement of radon and thoron released from building materials used in Japan, Prog. Nucl. Sci. Technol., 1, 404407 (2011).

15) S. Furuta, K. Ito and Y. Ishimori; Measurements of radon around closed uranium mines, J. Environ. Radioact., 62, 97-114 (2002).

16) S. Tokonami, Y. Ishimori, T. IshikaWa, K. Yamasaki and Y. YAMADA; Intercomparison exercise of measurement techniques for radon, radon decay products and their particle size distribution at NIRS, Jpn. J. Health Phys., 40, 183-190 (2005).

17) M. Janik, S. Tokonami, T. Kovács, N. Kávási, C. Kranrod, A. Sorimachi, H. Takahashi, N. Miyahara and T. IsHIKAWA; International intercomparisons of integrating radon detectors in the NIRS radon chambers, Appl. Radiat. 
Isotopes, 67, 1691-1696 (2009).

18) W. A. HAMMOND DRIERITE CO. LTD.; Drierite desiccant catalog. Available at: https://secure.drierite.com/ catalog3/page5.cfm, Accessed 24 May 2014.

19) H. Ichitsubo, Y. Yamada, A. Kolzumi and M. Shimo; Monitoring of radioactive contaminants in exhaust gas from radon experiment facility at NIRS, Jpn. J. Radiat. Saf. Manag., 4, 62-70 (2005) (in Japanese, with English abstract).

20) K. Ito, Y. Ishimori and S. Furuta; Radon progeny size distribution in and around closed uranium mine, In: Proceedings of the 10th International Congress of the International Radiation Protection Association (IRPA-10), pp. 15-19 (2000), Hiroshima Japan, 14-19 May, 2000.

21) Y. Tajika, Y. Yasuoka, H. Nagahama, T. Suzuki, Y. Homma, T. Ishikawa, S. Tokonami, T. Mukai, M. Janik, A. Sorimachi and M. Hosoda; Radon concentration of outdoor air: measured by an ionization chamber for radioisotope monitoring system at radioisotope institute, $J$. Radioanal. Nucl. Chem., 295, 1709-1714 (2013).
22) T. IIDA; An electrostatic radon monitor for the continuous measurement of environmental radon. S. OKAвE, (ed.) "Atmospheric Radon Families and Environmental Radioactivity”, pp. 197-202 (1985), Atomic Energy Society of Japan, Tokyo (in Japanese, with English abstract).

23) J. Porstendörfer; Properties and behaviour of radon and thoron and their decay products in the air, J. Aerosol. Sci., 25, 219-263 (1994).

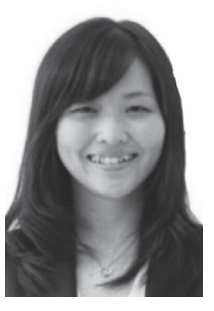

多鹿 優佳里（たじかゆかり）

2014 年 3 月神戸薬科大学卒業。日本保 健物理学会第 46 回研究発表会において, 優秀ポスター賞（学生の部）を受賞した 内容を論文発表。現在, 病院で薬剤師と して従事。ご連絡は下記の研究室まで。

E-mail: yasuoka@kobepharma-u.ac.jp 